\title{
Tos crónica un desafío para el siglo XXI
}

La tos crónica es una de las causas más frecuentes de consulta médica ${ }^{1}$ pudiendo llegar a ser la principal durante el período de invierno sobretodo en la atención pediátrica. Sin embargo, pese a esto la investigación científica así como el desarrollo farmacéutico habian sido bastante escasos y no era un tema de relevancia en la literatura cientifica. Afortunadamente esto ha cambiado y en las últimas décadas ha surgido gran interés en el estudio de la tos. En los últimos años al menos cinco importantes sociedades académicas de Enfermedades Respiratorias han publicado consensos o guías para el diagnóstico y manejo de esta condición ${ }^{2-6}$.

La necesidad de contar con guías de manejo, refleja la dificultad que puede tener el manejo de esta condición. La Sociedad Europea de Enfermedades Respiratorias en su "Guía de manejo de la tos" "7 además de dar pautas para el diagnóstico y tratamiento, da normas para promover y mejorar la calidad de la investigación en todas las áreas relacionadas con la tos.

Se han realizado conferencias internacionales sobre el tema, entre las que podemos citar el Primer Simposio Internacional de Tos el año 2008 en Londres 8 y la Segunda Conferencia Americana de Tos $^{8}$ en julio de 2009 en Nueva York, en ambas se revisaron temas de ciencias básicas, investigación y manejo clínico de la tos.

Actualmente, se están desarrollando y evaluando, en fases pre-clínicas y clínicas iniciales un buen número de nuevos fármacos antitusivos. Entre ellos los que más llaman la atención son los antagonistas de los canales iónicos de la superfamilia TRP (transient receptor potential) vainiloide subtipo 1 (TRPV1) y ankyrin subtipo 1 (TRPA1) ${ }^{10}$ y los canabinoides endógenos ${ }^{11}$. Además se están desarrollando equipos grabadores de tos cada vez más precisos y portátiles, con los cuales esperamos comprender y avanzar mucho en la fisiología del reflejo tusígeno ${ }^{12}$.

Es de esperar que los esfuerzos en curso tanto en ciencias básicas como en el escenario clínico logren proporcionar a los médicos más conocimiento como también mejores instrumentos diagnósticos y farmacológicos para tratar a esta compleja población de pacientes.

Es con este propósito que en las $18^{a}$ Jornadas de Invierno de la Sociedad Chilena de Enfermedades Respiratorias, realizadas entre el 21 y 22 de agosto de 2009, revisamos ampliamente este tema en sus aspectos fisiológicos, fisiopatológicos, farmacológicos y clínicos con la participación de destacados especialistas nacionales.

Peter $V$. Dicpinigaitis, $M D$

Professor of Clinical Medicine, Albert Einstein College of Medicine; Director, Intensive Care Unit, Weiler Division/Montefiore Medical Center; Director, Montefiore Cough Center. Bronx, New York, USA.

Dra. Patricia Schönffeldt G. Coordinadora $18^{a}$ Jornadas de Invierno Sociedad Chilena de Enfermedades Respiratorias 


\section{Bibliografía}

1.- BURT C W, SCHAPPERT S M. Ambulatory care visits to physician offices, hospital outpatient departments, and emergency departments: United States, 19992000. Vital Health Stat 13 2004; 157: 1-70.

2.- MORICE A H, FONTANA G A, SOVIJARVI A R A, PISTOLESI M, CHUNG F K, WIDDICOMBE J, et al. European Respiratory Society Task Force: the diagnosis and management of chronic cough. Eur Respir J 2004; 24: 481-92.

3.- IRWIN R S, BAUMANN M H, BOLSER D C, BOULET L P, BRUMAN S S, BRIGHTLING C E, et al. Diagnosis and management of cough executive summary: ACCP evidence-based clinical practice guidelines. Chest 2006; 129 (suppl): 1S-23S.

4.- MORICE A H, MCGARVEY L, PAVORD I. British Thoracic Society Cough Guideline Group. Recommendations for the management of cough in adults. Thorax 2006; 61 (suppl 1): 1-24.

5.- KOHNO S, ISHIDA T, UCHIDA Y, KISHIMOTO H, SASAKI H, SHIOYA T, et al. The Japanese Respiratory Society guidelines for the management of cough. Respirology 2006; 11 (suppl 4): S135-86.
6.- KARDOS P, CEGLA U, GILLISSEN A, KIRSTEN D, MITFESSEL H, MORR H, et al. The German Respiratory Society's guideline for the diagnosis and treatment of patients with acute and chronic cough. Med Klin (Munich) 2004; 99: 468-75.

7.- MORICE A H, FONTANA G A, BELVISI M G, BIRRING S S, CHUNG K F, DICPINIGAITIS P, et al. European Respiratory Society guidelines on the assessment of cough. Eur Respir J 2007; 29: 1256-76.

8.- CHUNG K F, WIDDICOMBE J. The 2008 Fifth International Cough Symposium: mechanisms and treatment. Pulm Pharmacol Ther 2009; 22: 57-8.

9.- DICPINIGAITIS P V. The Second American Cough Conference. Lung 2009, July 28 [Epub ahead of print]; PMID 19636621.

10.- MCLEOD R L, CORRELL C C, JIA Y, ANTHES J C. TRPV1 antagonists as potential antitussive agents. Lung 2008; 186 (Suppl 1): S59-S65.

11.- BELVISI M G. Preclinical assessment of novel therapeutics on the cough reflex: cannabinoid agonists as potential antitussives. Lung 2008; 186 (Suppl 1): S66-9.

12.- SMITH J, WOODCOCK A. New developments in the objective assessment of cough. Lung 2008; 186 (Suppl 1): S48-S54. 